\title{
Grey Matter Volume Differences Associated with Extremely Low Levels of Cannabis Use in Adolescence
}

\author{
Catherine Orr, ${ }^{1,2}$ Philip Spechler, ${ }^{1}$ Zhipeng Cao, ${ }^{3,4}$ Matthew Albaugh, ${ }^{1}$ Bader Chaarani, ${ }^{1}$ Scott Mackey, ${ }^{1}$ \\ Deepak D’Souza, ${ }^{5}{ }^{\oplus N i c h o l a s ~ A l l g a i e r, ~}{ }^{1}$ Tobias Banaschewski, ${ }^{6}{ }^{\circledR}$ Arun L.W. Bokde, ${ }^{7}$ Uli Bromberg, ${ }^{8}$ Christian Büchel, ${ }^{8}$ \\ Erin Burke Quinlan, ${ }^{9}$ Patricia Conrod, ${ }^{10,11,12}$ Sylvane Desrivières, ${ }^{9}{ }^{\circ}$ Herta Flor, ${ }^{13,14}$ Vincent Frouin, ${ }^{15}$ \\ (DPenny Gowland, ${ }^{16}$ Andreas Heinz, ${ }^{17}$ Bernd Ittermann, ${ }^{18}$ Jean-Luc Martinot, ${ }^{19}$ Marie-Laure Paillère Martinot, ${ }^{20}$
} Frauke Nees, ${ }^{6,13}$-Dimitri Papadopoulos Orfanos, ${ }^{15}$ Tomáš Paus, ${ }^{21}$ Luise Poustka ${ }^{22,23}$ Sabina Millenet, ${ }^{6}$ Juliane H. Fröhner, ${ }^{24}$ Rajiv Radhakrishnan, ${ }^{5}$ Michael N. Smolka, ${ }^{24}$ Henrik Walter, ${ }^{17}$ ORobert Whelan, ${ }^{3,4}$ Gunter Schumann, ${ }^{9}$ Alexandra Potter, ${ }^{1}$ and Hugh Garavan ${ }^{1}$

${ }^{1}$ Departments of Psychiatry and Psychology, University of Vermont, Burlington, Vermont 05405, ${ }^{2}$ Department of Psychological Sciences, Swinburne University of Technology, Hawthorn, Victoria 3122, Australia, ${ }^{3}$ Department of Psychology, University College Dublin, Dublin 4, Ireland, ${ }^{4}$ Department of Psychology and Institute of Neuroscience, Trinity College Dublin, Dublin 2, Ireland, ${ }^{5}$ Department of Psychiatry, Yale University School of Medicine, West Haven, Connecticut 06516, ' Department of Child and Adolescent Psychiatry and Psychotherapy, Central Institute of Mental Health, Medical Faculty Mannheim, Heidelberg University, 68159 Mannheim, Germany, ${ }^{7}$ Discipline of Psychiatry, School of Medicine and Trinity College Institute of Neuroscience, Trinity College Dublin, Dublin 2, Ireland, ${ }^{8}$ University Medical Centre Hamburg-Eppendorf, 20246, Hamburg, Germany, ${ }^{9}$ Centre for Population Neuroscience and Stratified Medicine (PONS) and MRC-SGDP Centre, Institute of Psychiatry, Psychology and Neuroscience, King's College London, WC2R 2LS United Kingdom, ${ }^{10}$ Centre de recherche du CHU Ste-Justine and ${ }^{11}$ Department of Psychiatry, Université de Montréal, 3175 Chemin de la Côte SainteCatherine, Montreal, Québec H3T 1C5, Canada, ${ }^{12}$ National Addiction Centre, Institute of Psychiatry, Psychology and Neuroscience (IoPPN), King's College London, Addiction Sciences Building, London SE5 8BB, United Kingdom, ${ }^{13}$ Department of Cognitive and Clinical Neuroscience, Central Institute of Mental Health, Medical Faculty Mannheim, Heidelberg University, 68159 Mannheim, Germany, ${ }^{14}$ Department of Psychology, School of Social Sciences, University of Mannheim, 68131 Mannheim, Germany, ${ }^{15}$ NeuroSpin, CEA, Université Paris-Saclay, F-91191 Gif-sur-Yvette, France, ${ }^{16}$ Sir Peter Mansfield Imaging Centre School of Physics and Astronomy, University of Nottingham, University Park, Nottingham, NG7 2RD United Kingdom, ${ }^{17}$ Department of Psychiatry and Psychotherapy, Campus Charité Mitte, Charité, Universitätsmedizin Berlin, 10117 Berlin, Germany, ${ }^{18}$ Physikalisch-Technische Bundesanstalt (PTB), Braunschweig and Berlin, Germany, Berlin, 10587 Germany, ${ }^{19}$ Institut National de la Santé et de la Recherche Médicale, INSERM Unit 1000 "Neuroimaging and Psychiatry", University Paris Sud-University Paris Saclay, DIGITEO Labs, 91190 Gif sur Yvette, France, ${ }^{20}$ Institut National de la Santé et de la Recherche Médicale, INSERM Unit 1000 "Neuroimaging and Psychiatry", and AP-HP, Department of Adolescent Psychopathology and Medicine, Maison de Solenn, Cochin Hospital, 75014 Paris, France, ${ }^{21}$ Rotman Research Institute, Baycrest, and Departments of Psychology and Psychiatry, University of Toronto, Toronto, Ontario M6A 2E1, Canada, ${ }^{22}$ Department of Child and Adolescent Psychiatry and Psychotherapy, University Medical Centre Göttingen, 37075, Göttingen, Germany, ${ }^{23}$ Clinic for Child and Adolescent Psychiatry, Medical University of Vienna, 1090, Vienna, Austria, and ${ }^{24}$ Department of Psychiatry and Neuroimaging Center, Technische Universität Dresden, Dresden, 01069 Germany

Rates of cannabis use among adolescents are high, and are increasing concurrent with changes in the legal status of marijuana and societal attitudes regarding its use. Recreational cannabis use is understudied, especially in the adolescent period when neural maturation may make users particularly vulnerable to the effects of $\Delta$-9-tetrahydrocannabinol (THC) on brain structure. In the current study, we used voxel-based morphometry to compare gray matter volume (GMV) in forty-six 14-year-old human adolescents (males and females) with just one or two instances of cannabis use and carefully matched THC-naive controls. We identified extensive regions in the bilateral medial temporal lobes as well as the bilateral posterior cingulate, lingual gyri, and cerebellum that showed greater GMV in the cannabis users. Analysis of longitudinal data confirmed that GMV differences were unlikely to precede cannabis use. GMV in the temporal regions was associated with contemporaneous performance on the Perceptual Reasoning Index and with future generalized anxiety symptoms in the cannabis users. The distribution of GMV effects mapped onto biomarkers of the endogenous cannabinoid system providing insight into possible mechanisms for these effects.

Key words: adolescent substance use; cannabis; cognition; marijuana; psychopathology; voxel-based morphometry

Significance Statement

Almost 35\% of American 10th graders have reported using cannabis and existing research suggests that initiation of cannabis use in adolescence is associated with long-term neurocognitive effects. We understand very little about the earliest effects of cannabis use, however, because most research is conducted in adults with a heavy pattern of lifetime use. This study presents evidence suggesting structural brain and cognitive effects of just one or two instances of cannabis use in adolescence. Converging evidence suggests a role for the endocannabinoid system in these effects. This research is particularly timely as the legal status of cannabis is changing in many jurisdictions and the perceived risk by youth associated with smoking cannabis has declined in recent years. 


\section{Introduction}

Preclinical evidence has consistently demonstrated a causal relationship between cannabis exposure and changes to brain morphology (for review, see Panlilio and Justinova, 2018). The human evidence, however, has been variable reporting both increases and decreases in brain volumes (Ashtari et al., 2011; Cousijn et al., 2012; Gilman et al., 2014), no volume differences (Jager et al., 2007; Weiland et al., 2015; Gillespie et al., 2018), and modest effect sizes (Weiland et al., 2015). Factors including the age of cannabis use initiation, comorbid substance use, and levels of use are believed to contribute to variability in the human findings (Curran et al., 2016).

Most neuroimaging research is conducted in adults with a heavy, chronic pattern of cannabis use and does not reflect most people's experience, which is recreational (SAMHSA, 2014). Dose-dependent associations with brain volumes have been reliably identified in preclinical studies (for review, see Lorenzetti et al., 2010) with some evidence of the same in humans (Battistella et al., 2014; French et al., 2015), suggesting consequences of lower levels of use. One study has reported differences in gray-matter density and shape of the amygdala and nucleus accumbens in recreational cannabis users (Gilman et al., 2014), but subsequent research has suggested that these findings may be associated with alcohol (Weiland et al., 2015) and nicotine (Gillespie et al., 2018) exposure in the cannabis users.

One mechanism by which cannabis may produce neurobiological changes is through the endogenous cannabinoid system (eCB). The amygdala, hippocampus, striatum, and cerebellum (Lorenzetti et al., 2016) are regions most frequently showing

Received Dec. 1, 2017; revised Dec. 3, 2018; accepted Dec. 11, 2018.

Author contributions: C.O. wrote the first draft of the paper; C.O., P.S., Z.C., M.A., B.C., S. Mackey, D.D., N.A., T.B., A.L.W.B., U.B., C.B., E.B.Q., P.C., S.D., H.F., V.F., P.G., A.H., B.I., J.-L.M., M.-L.P.M., F.N., D.P.O., T.P., L.P., R.R., S. Millenet, J.H.F., M.N.S., H.W., R.W., G.S., A.P., and H.G. edited the paper; T.B., A.L.W.B., U.B., C.B., E.B.Q., P.C., S.D., H.F., V.F., P.G., A.H., B.I., J.-L.M., M.-L.P.M., F.N., D.P.O., T.P., L.P., S. Millenet, J.F., M.N.S., H.W., R.W., G.S., and H.G. designed research; C.O., D.D., T.B., A.L.W.B., U.B., C.B., E.B.Q., P.C., S.D., H.F., V.F., P.G., A.H., B.I., J.-L.M., M.-L.P.M., F.N., D.P.O., T.P., L.P., S. Millenet, J.F., M.N.S., H.W., R.W., G.S., and H.G. performed research; C.O., P.S., Z.C., M.A., B.C., S. Mackey, D.D., N.A., R.R., and R.W. analyzed data; C.O. and H.G. wrote the paper.

This work received support from the following sources: the European Union-funded FP6 Integrated Project IMAGEN (Reinforcement-related behavior in normal brain function and psychopathology; LSHM-CT-2007-037286), the Horizon 2020 funded ERC Advanced Grant "STRATIFY" (Brain network based stratification of reinforcementrelated disorders; 695313), ERANID (Understanding the Interplay between Cultural, Biological and Subjective Factors in Drug Use Pathways; PR-ST-0416-10004), BRIDGET (JPND: BRain Imaging, cognition Dementia and next generation GEnomics; MR/N027558/1), the FP7 projects IMAGEMEND(602450; IMAging GEnetics for MENtal Disorders) and MATRICS (603016), the Innovative Medicine Initiative Project EU-AIMS (115300-2), the Medical Research Council Grant "C-VEDA" (Consortium on Vulnerability to Externalizing Disorders and Addictions; MR/N000390/1), the Swedish Research Council FORMAS, the Medical Research Council, the National Institute for Health Research Biomedical Research Centre at South London and Maudsley NHS Foundation Trust and King's College London, the Bundesministeriumfür Bildung und Forschung (BMBF Grants 01GS08152; 01EV0711; eMED SysAlc01ZX1311A; Forschungsnetz AERIAL), the Deutsche Forschungsgemeinschaft (DFG Grants SM 80/7-1, SM 80/7-2, SFB 940/1), and the Fondation pour la Recherche Médicale (DPA20140629802), the Fondation de l'Avenir. Further support was provided by Grants from: ANR (project AF12-NEUR0008-01-WM2NA, and ANR-12-SAMA-0004), the Fondation de France, the Fondation pour la Recherche Médicale, the Mission Interministérielle de Lutte-contre-les-Drogues-etles-Conduites-Addictives, the Assistance-Publique-Hôpitaux-de-Paris and INSERM (interface Grant), Paris Sud University IDEX 2012; the National Institutes of Health, Science Foundation Ireland (16/ERCD/3797), (Axon, Testosterone, and Mental Health during Adolescence; R01 MH085772-01A1), and by NIH Consortium Grant U54 EB020403, supported by a cross-NIH alliance that funds Big Data to Knowledge Centers of Excellence. R.R. is supported by Dana Foundation David Mahoney program and CTSA Grant Number UL1 TR001863 from the National Center for Advancing Translational Science, components of the National Institutes of Health (NIH), and NIH roadmap for Medical Research, and C.0. received support Faculty of Health, Arts, and Design, Swinburne University of Technology to attend the FHAD writing retreat.

Dr. Banaschewski served in an advisory or consultancy role for Actelion, Hexal Pharma, Lilly, Lundbeck, Medice, Novartis, and Shire; received conference support or speaker's fee by Lilly, Medice, Novartis, and Shire; has been involved in clinical trials conducted by Shire and Viforpharma; and received royalties from Hogrefe, Kohlhammer, CIP Medien, and Oxford University Press. The present work is unrelated to the above grants and relationships.

The remaining authors declare no competing financial interests.

Correspondence should be addressed to Catherine Orr at corr@swin.edu.au.

https://doi.org/10.1523/JNEUROSCI.3375-17.2018

Copyright $\odot 2019$ the authors $\quad 0270-6474 / 19 / 391818-11 \$ 15.00 / 0$ structural brain correlates of cannabis use and are also components of the eCB system (Burns et al., 2007); the preclinical literature suggests a causal role of this system in the effects of cannabis on brain morphology (Downer et al., 2001). The eCB system mediates maturation-related neural reorganization (FernándezRuiz et al., 2000), which may place adolescents at heightened vulnerability to structural brain effects of cannabis exposure as adolescence is a time of rapid neural maturation (Rubino and Parolaro, 2008). Consistent with this suggestion, those who commenced cannabis use in adolescence typically show greater structural brain differences than those who initiated use in adulthood (Battistella et al., 2014; Lubman et al., 2015). These findings may also have been influenced by the effects of other substances, however, as one study comparing adolescent daily cannabis users with controls matched for alcohol and nicotine use found no differences in subcortical gray-matter density or morphology (Weiland et al., 2015).

In the present study we identified participants with just one or two instance of cannabis use from a very large, population sample of adolescents (IMAGEN, $n=2400$; Schumann et al., 2010) and control participants matched on a range of variables, including alcohol and nicotine consumption. We predicted that even extremely low levels of cannabis use would be associated with structural brain differences in regions previously implicated in cannabis use studies and in the eCB system: the amygdala, hippocampus, striatum, and cerebellum. We adopted a whole-brain, voxel-based morphometry (VBM) approach as it allows us to also test more extensive regions of the eCB system including the frontal cortex and posterior cingulate (Burns et al., 2007). We explored whether gray matter volume (GMV) predicted behavioral features previously associated with cannabis use and with the eCB system.

To test whether observed differences between cannabis users and controls may precede cannabis use, we also identified participants who were cannabis-naive at the time of imaging but went on to use cannabis 2 years later and matched controls who remained abstinent. Finally, to demonstrate association with the eCB system, we compared the spatial distribution of GMV effects with two biomarkers of the eCB system using $\mathrm{CB}_{1}$ receptor availability taken from a previously published, independent sample (D'Souza et al., 2016) and the expression of the CNR1 gene, which encodes this receptor, taken from the Allen Human Brain Atlas (Hawrylycz et al., 2012).

\section{Materials and Methods}

\section{Standard operating procedures}

Standard operating procedures for the IMAGEN project are available at https://imagen-europe.com/resources/standard-operating-procedures/ and contain details on ethics, recruitment, and assessment.

\section{Participants}

Data were acquired from a large sample of adolescents recruited through high schools in four European countries for the IMAGEN project (http:// www.imagen-europe.com). Recruitment into the IMAGEN study was managed through eight sites and targeted adolescents for whom all four grandparents were the same nationality as the participant; as such, the sample is racially and ethnically homogenous. Raw, T1-weighted images were visually inspected for the presence of anatomical abnormalities or artifacts including head motion or reconstruction errors. After VBM processing, images were again inspected for any errors in tissue segmentation or normalization into MNI space. Images failing quality control for any reason were excluded.

Cohort 1. Forty-seven participants reported low levels of cannabis use at baseline (only 1 or 2 lifetime instances of use) and complete demo- 
Table 1. Demographic characteristics of Cohort 1, those 14 year olds reporting 1 or 2 instances of cannabis use $(n=46)$ and matched controls $(n=46)$

\begin{tabular}{|c|c|c|c|}
\hline Variable & Cannabis & Control & Statistic \\
\hline \multicolumn{4}{|l|}{ Mean } \\
\hline Age & 14.60 & 14.51 & $t_{(90)}=1.06$ \\
\hline PDS & 3.04 & 2.95 & $t_{(90)}=0.846$ \\
\hline $\mathrm{VCl}$ & 108.33 & 108.20 & $t_{(90)}=0.042$ \\
\hline PRI & 102.85 & 103.77 & $t_{(90)}=0.345$ \\
\hline SES & 18.80 & 18.72 & $t_{(90)}=0.091$ \\
\hline Total GMV, mm ${ }^{3}$ & $74,2955.12$ & $72,8559.92$ & $t_{(90)}=1.03$ \\
\hline Lifetime alcohol consumption & 3.46 & 3.52 & $t_{(90)}=0.214$ \\
\hline Lifetime nicotine consumption & 2.54 & 2.59 & $t_{(90)}=0.101$ \\
\hline Average age of first cannabis use & 13.83 years & & \\
\hline \multicolumn{4}{|l|}{ Summary } \\
\hline Sex & $65 \%$ male & $48 \%$ male & $U=874$ \\
\hline Handedness & $87 \%$ right handed & $87 \%$ right handed & $U=1058$ \\
\hline Site 1 & 3 & 2 & $U=1081$ \\
\hline Site 2 & 12 & 7 & $U=1173$ \\
\hline Site 3 & 4 & 1 & $U=1127$ \\
\hline Site 4 & 6 & 8 & $U=1012$ \\
\hline Site 5 & 7 & 8 & $U=1035$ \\
\hline Site 6 & 3 & 8 & $U=943$ \\
\hline Site 7 & 11 & 12 & $U=1035$ \\
\hline Site 8 & 0 & 0 & \\
\hline $\begin{array}{l}\text { No. reporting cannabis use } \\
\text { in the past } 30 \mathrm{~d}(\%)\end{array}$ & $10(21.74)$ & & \\
\hline $\begin{array}{l}\text { No. reporting cannabis use } \\
\text { in the past } 7 \mathrm{~d}(\%)\end{array}$ & $6(13.04)$ & & \\
\hline
\end{tabular}

graphics to facilitate matching; one participant was excluded because of poor scan quality, leaving 46 adolescent cannabis using participants. The groups were matched on age, sex, handedness, pubertal development, intelligence quotient (IQ; verbal comprehension and perceptual reasoning index scores), socioeconomic status (SES), total GMV, alcohol use, and nicotine use across group. All participants denied any other illicit substance use, and none reported using the fictional control substance, relevin, supporting the integrity of the self-report metrics. Table 1 summarizes the demographic information. We also ensured that similar numbers of cannabis users and controls were selected from each site (Mann-Whitney $U$ tests; Table 1) and confirmed that the proportion of cannabis users and controls did not differ by site using a Kruskal-Wallis test $\left(\chi_{(6)}^{2}=5.919, p=0.432\right)$.

For a subset of the 14-year-old cannabis-using participants, data were available at 2 year follow-up for substance use, cognitive ability, and psychopathology at age 16 to allow us to assess the implications of cannabis-related GMV differences for future functioning in these domains. Table 2 summarizes the demographic information for this subset of participants.

Cohort 2. To determine whether group differences between cannabis users and matched controls may have preceded cannabis use, we also identified participants who were cannabis-naive at the age 14 baseline assessment but reported at least 10 instances of cannabis use by follow-up 2 years later. Sixty-nine participants who were cannabisnaive at baseline but with at least 10 instances of cannabis use by follow-up provided complete demographic data and all had GMV data that passed QC. Sixty-nine controls matched by group on the same demographic measures as above and who reported no cannabis use at baseline or follow-up were also identified. All participants denied any other illicit substance use at baseline and follow-up. Table 3 summarizes the demographic information for this sample of participants. We again ensured that similar numbers of cannabis users and controls were selected from each site (Mann-Whitney $U$ tests; Table 3 ) and confirmed that the proportion of cannabis users and controls did not differ by site using a Kruskal-Wallis Test $\left(\chi_{(7)}^{2}=4.633, p=\right.$ $0.705)$.
Table 2. Demographic characteristics for those members of Cohort 1 for whom specific substance use, psychopathology, and cognitive measures were available at 16 year old follow-up

\begin{tabular}{|c|c|c|c|}
\hline & $\begin{array}{l}\text { Substance } \\
\text { use }(n=31)\end{array}$ & $\begin{array}{l}\text { Psychopathology } \\
(n=33)\end{array}$ & $\begin{array}{l}\text { Delay discounting } \\
(n=31)\end{array}$ \\
\hline \multicolumn{4}{|l|}{ Mean } \\
\hline Age & 14.60 & 14.60 & 14.58 \\
\hline PDS & 3.04 & 3.04 & 3.03 \\
\hline $\mathrm{VCl}$ & 110.19 & 110.31 & 110.46 \\
\hline PRI & 103.91 & 103.36 & 103.87 \\
\hline SES & 19.01 & 19.47 & 19.40 \\
\hline Total GMV, $\mathrm{mm}^{3}$ & $74,2793.69$ & $74,1208.83$ & $74,2428.43$ \\
\hline $\begin{array}{l}\text { Lifetime alcohol } \\
\text { consumption }\end{array}$ & 3.61 & 3.64 & 3.61 \\
\hline $\begin{array}{l}\text { Lifetime nicotine } \\
\text { consumption }\end{array}$ & 2.48 & 2.45 & 2.39 \\
\hline \multicolumn{4}{|l|}{ Summary } \\
\hline Sex, $\%$ & 61 male & 61 male & 61 male \\
\hline Handedness, $\%$ & 90 right handed & 88 right handed & 87 right handed \\
\hline
\end{tabular}

Table 3. Demographic characteristics of Cohort 2, those 16 year olds who were abstinent for cannabis use at baseline (age 14) but reported 10 or more instances of cannabis use by age $16(n=69)$ and matched controls $(n=69)$

\begin{tabular}{lccl}
\hline Variable & Cannabis & Control & Statistic \\
\hline Mean & & & \\
Age & 14.43 & 14.50 & $t_{(136)}=0.944$ \\
PDS & 2.80 & 2.79 & $t_{(136)}=0.290$ \\
VCl & 112.48 & 110.29 & $t_{(136)}=0.859$ \\
PRI & 109.16 & 108.26 & $t_{(136)}=0.367$ \\
SES & 17.97 & 17.42 & $t_{(136)}=0.835$ \\
Total GMV, mm ${ }^{3}$ & $75,5082.71$ & $74,7752.65$ & $t_{(136)}=0.647$ \\
Lifetime alcohol & 2.33 & 2.29 & $t_{(136)}=0.166$ \\
consumption & & & \\
Lifetime nicotine & 1.33 & 1.16 & $t_{(136)}=0.577$ \\
consumption & & & \\
Average age of first & 14.97 & & \\
cannabis use, y & & & \\
Summary & & & \\
Sex & $74 \%$ male & $70 \%$ male & $U=2277$ \\
Handedness & $93 \%$ right handed & $91 \%$ right handed & $U=2346$ \\
Site 1 & 3 & 7 & $U=2242.5$ \\
Site 2 & 11 & 9 & $U=2449.5$ \\
Site 3 & 4 & 3 & $U=2415$ \\
Site 4 & 8 & 6 & $U=2449.5$ \\
Site 5 & 11 & 10 & $U=2415$ \\
Site 6 & 8 & 13 & $U=2208$ \\
Site 7 & 15 & 10 & $U=2553$ \\
Site 8 & 9 & 11 & $U=2311.5$ \\
\hline
\end{tabular}

For both cohorts, the control subjects were selected from a larger pool of IMAGEN participants with T1 images that passed QC and who reported no illicit substance use. This selection was done using Python scripts written in our laboratory to randomly select subjects and compare them with the sample of cannabis users on nominated characteristics (in this case: age, sex, handedness, site (dummy coded as 8 binary variables), pubertal development, VCIQ, PRIQ, SES, total GMV, alcohol use, and nicotine use) without experimenter intervention.

Substance use measures

Substance use was assessed at baseline (age 14) and follow-up (age 16) via the European School Survey Project on Alcohol and Drugs (ESPAD; Hibell et al., 2004), a self-report questionnaire that measures use of alcohol, nicotine, cannabis, inhalants, tranquilizers, amphetamines, lysergic acid diethylamide (LSD), magic mushrooms, crack, cocaine, heroin, narcotics, methylenedioxymethamphetamine (MDMA), ketamine, $\gamma$-hydroxybutyric acid (GHB), anabolic steroids, and a fictional 
control measure (relevin). Participants indicated how frequently they had used each of the substances in their lifetime, in the past 12 months, in the past $30 \mathrm{~d}$, and in the past $7 \mathrm{~d}$ using a 7 -point scale (0: never, $1: 1-2$ times, $2: 3-5$ times, $3: 6-9$ times, $4: 10-19$ times, $5: 20-39$ times, and 6:40 or more times); they also indicated the age at which they had first tried each of the substances.

Cohort 1 comprised those participants with an ESPAD of 1 for cannabis (i.e., 1-2 instances of cannabis use) and no reported use of any other illicit substances, and matched controls with no cannabis use and no use of any other illicit substances. We also extracted lifetime alcohol and nicotine use from the ESPAD to match the groups on these variables. To explore possible relationships between GMV and cannabis use metrics, we also extracted from the ESPAD age of first use, frequency of use in the past $30 \mathrm{~d}$, and lifetime use by age 16 for those who reported cannabis use at baseline.

Cohort 2 comprised those participants with an ESPAD of 0 for cannabis at baseline, an ESPAD of 4, 5, or 6 for cannabis at follow-up (i.e., cannabis-naive at age 14 and with $10+$ instances of cannabis use by age 16) and no reported use of any other illicit substances at either baseline or follow-up, and matched controls with no cannabis use and no use of any other illicit substances at either time point. We also extracted lifetime alcohol and nicotine use from the ESPAD to match the groups on these variables.

\section{Demographic measures}

Biological sex was determined by karyotype analysis (chromosome 23: $\mathrm{XX}=$ female, $\mathrm{XY}=$ male). Participants provided blood samples, which were shipped to the Institute of Psychiatry, London for genotyping with Illumina Human610-Quad Bead Chips (Illumina). DNA extraction was performed by a semiautomated process to ensure high quality and sufficient quantity (Schumann et al., 2010).

SES was indexed by a score that summed: Mother's Education Score, Father's Education Score, Family Stress Unemployment Score, Financial Difficulties Score, Home Inadequacy Score, Neighborhood Score, Financial Crisis Score, Mother Employed Score, and Father Employed Score from the parent report of the Development and Well-Being Assessment interview (DAWBA; Goodman et al., 2000; http://www.dawba.info).

Participants completed the Perceptual Reasoning, Matrix Reasoning, Similarities and Vocabulary subscales from the Wechsler intelligence scale for children WISC-IV(Wechsler, 1949) to generate Verbal Comprehension (VCIQ) and Perceptual Reasoning (PRIQ) indices.

Physical maturity was assessed using the Pubertal Development Scale (Petersen et al., 1988), a self-report measure of physical signs associated with the onset, progression, and completion of puberty.

\section{Personality and temperament measures}

Personality was assessed with the self-reported Substance Use Risk Profile Scale (SURPS; Woicik et al., 2009), the NEO Five Factor Inventory (NEO-FFI; Costa and McCrae, 1992), and the Temperament and Character Inventory (TCI; Cloninger et al., 1994). The SURPS produced summary measures for personality traits of hopelessness, anxiety sensitivity, impulsivity, and sensation-seeking. The NEO-FFI produced summary measures for five higher-order personality characteristics: neuroticism, conscientiousness, extraversion, agreeableness, and openness to experience. The TCI produced measures for exploratory excitability versus stoic rigidity, impulsiveness versus reflection, extravagance versus reserve, disorderliness versus regimentation, and a novelty-seeking summary statistic.

\section{Cognitive measures}

Delay discounting was assessed with the Monetary Choice Questionnaire (Kirby, 2009) that required participants to complete 27 two-alternative forced-choice items in which they indicated whether they would prefer a "smaller sooner" or a "larger later" reward (e.g., "Would you prefer $€ 14$ today or $€ 25$ in $19 \mathrm{~d}$ ?"). The summary $k$ statistic indexes the degree to which a participant discounts more temporally remote rewards.

Psychomotor speed and manual dexterity were assessed using the Perdue Pegboard (Tiffin, 1968). Participants were asked to place as many pins as possible in the small holes on the test board in $30 \mathrm{~s}$. Participants completed three trials in each of three conditions: using only the dominant hand; only the non-dominant hand; and both hands.

Spatial working memory and decision-making were assessed using the Cambridge Neuropsychological Test Automated Battery (CANTAB; Robbins et al., 1994). We examined the number of memory failures made during a visual search task and the risk-taking summary statistic from a gambling task.

\section{Psychopathology measures}

Psychiatric symptoms of conduct disorder, oppositional defiant disorder, attention deficit/ hyperactivity disorder, generalized anxiety, depression, specific phobia, social phobia, agoraphobia, panic disorder, obsessive compulsive disorder, and eating disorders were assessed via the DAWBA, which was administered to participants and their parents at baseline and at follow-up. Computer generated band scores integrated reported symptoms and their impact with the approximate prevalence rates in an epidemiological sample for each disorder and reflect the likelihood that the participant would be diagnosed with the disorder in question (ranging from 0 to 5). Diagnostic criteria were based on the Diagnostic Statistical Manual, version 4.

\section{Neuroanatomical MRI acquisition}

MRI scanning was conducted at the eight IMAGEN assessment sites using 3T whole-body MRI systems (Siemens, 4 sites; Philips, 2 sites; General Electric, 1 site; Bruker, 1 site). A high-resolution, threedimensional T1-weighted image was acquired using a magnetization prepared gradient echo sequence based on the ADNI protocol (http:// adni.loni.usc.edu/methods/mri-tool/mri-analysis/), which specifies protocols designed to minimize differences in image contrast and signal-tonoise across scanner makes and models. Two additional quality control procedures were regularly implemented: (1) the American College of Radiology phantom was scanned every 2 months at each site and after every hardware and software upgrade to provide information about geometric distortions and signal uniformity related to hardware differences in radiofrequency coils and gradient systems, image contrast, and temporal stability; and (2) twice per year at each site and after any hardware or software upgrade, human volunteers were scanned to determine intersite variability in raw MRI signal and tissue relaxation properties (Schumann et al., 2010).

\section{Voxel-based morphometry}

T1-weighted images were processed using the Statistical Parametric Mapping v8 (SPM8; http://www.fil.ion.ucl.ac.uk/spm/software/spm8/) VBM toolbox (http://dbm.neuro.uni-jena.de/vbm/) with default parameters incorporating the DARTEL toolbox implemented in MATLAB 7.0 (MathWorks). Image processing comprised iterative tissue segmentation and spatial normalization using both linear (12-parameter affine) and nonlinear transformations (Ashburner and Friston, 2000; Ashburner, 2007) without skull stripping. SPM8 default settings were used to be consistent with other VBM publications from the IMAGEN Consortium. To preserve information about absolute volume, the gray matter concentration images were modulated by multiplying by the linear and nonlinear components of the Jacobian determinants generated during spatial normalization. Thus, the dependent measure in the subsequent analysis was absolute gray matter volume. Voxel resolution after normalization was $1.5 \times 1.5 \times 1.5 \mathrm{~mm}$. To make the residuals in later analyses conform more closely to a Gaussian distribution and to account for individual differences in brain anatomy, the modulated GM images were smoothed with an isotropic Gaussian kernel of $8 \mathrm{~mm}$ full-width at half-maximum.

\section{Experimental design and statistical analyses}

Whole-brain voxelwise analyses were conducted using the general linear model, implemented in AFNI (Cox, 1996). We tested for GMV differences at baseline between: (1) Cohort 1, those 46 participants who reported low levels of cannabis use at baseline and their matched controls; and (2) Cohort 2, those 69 participants who reported cannabis use by age 16 and their matched controls. Age, sex, handedness, and total GMV were included in the models as covariates of no interest. Imaging site was included as an additional covariate; given the cohort sizes and large num- 
ber of covariates already used, additional measures inter-site imaging variance were not included in this analysis. Type 1 error was controlled using a combination of voxel-level significance and cluster extent: following Eklund et al. (2016), the updated AFNI program 3dTTest ++ with the option -clustsim (https://afni.nimh.nih.gov/pub/dist/doc/ program_help/3dttest ++ .html) was used to determine the cluster extent of contiguous significant voxels required to adequately correct for multiple comparisons. Within a gray matter mask, significant voxels $(p<0.001)$ were required to be part of a cluster of at least 600 voxels $(2025 \mu \mathrm{l})$ to maintain familywise error at 5\%. Anatomic regions implicated by these clusters were determined by the AAL Atlas. Given that the AAL atlas does not label the ventral striatum (VS), we used the OxfordGSK-Imanova structural striatal atlas (Tziortzi et al., 2011) to separate the VS from the caudate and putamen.

We also conducted region-of-interest analyses in Cohort 2 in which we extracted GMV from the regions showing significant volume differences between baseline users and controls to confirm that GMV differences in these specific regions did not precede cannabis use. Note that these regions were defined by the analysis of Cohort $1(n=46)$, and then tested on an independent cohort (Cohort 2, $n=69$ ).

A series of post hoc analyses were conducted to ensure that group differences in GMV between baseline users and controls could not be accounted for by any differences in cognitive ability, personality, or symptoms of psychopathology. Independent groups $t$ tests were used to test for differences in the continuous variables and Mann-Whitney $U$ tests were used to test for differences in the ordinal DAWBA band scores. We did not correct for multiple comparisons for these tests so as to have a liberal threshold for identifying any group differences. We then repeated the voxelwise GMV analyses with any behavioral variables that differed between the groups included as additional covariates.

We explored whether individual differences in GMV in those regions that differed between cannabis users and controls were associated with substance use factors (lifetime alcohol or nicotine consumption, recent cannabis use, or age of onset of cannabis use) in those participants reporting cannabis use at baseline. We also assessed whether GMV in regions that differed between cannabis users and controls were associated with individual differences in specific cognitive and psychopathological domains previously related to cannabis misuse in those participants reporting cannabis use. Spatial working memory, risk-taking, delay discounting, psychomotor speed, depression, generalized anxiety, and ADHD were assessed at baseline. For a subset of those participants reporting cannabis use at baseline, psychopathology $(n=33)$, delay discounting $(n=31)$, and substance misuse data $(n=31)$ were also available at follow-up 2 years later. We assessed whether regional GMV at baseline predicted symptoms of depression, generalized anxiety, or ADHD; delay discounting; or future cannabis use. For all post hoc analyses, regional GMV was normalized by total GMV.

Cannabinoid 1 receptor availability. To test for associations between the spatial distribution of group differences in GMV and a receptor for the eCB system, we used a map of $\mathrm{CB}_{1}$ receptor availability generated from the healthy control participants in a previously published study (D'Souza et al., 2016). Maps of $\mathrm{CB}_{1}$ receptor availability were generated using positron emission tomography and the reversible ligand $\left[{ }^{11} \mathrm{C}\right] \mathrm{O}-$ MAR in 21 adult males aged 18-35 (D'Souza et al., 2016), the 21 individual participant maps were averaged to provide an estimate of $\mathrm{CB}_{1}$ receptor availability at each voxel.

The map of the GMV comparison between cannabis users and controls was downsampled to the resolution of the PET map $(3 \times 3 \times$ $3 \mathrm{~mm}^{3}$ voxels) and Spearman correlations were conducted between the $t$ statistic at each voxel and the average $\mathrm{CB}_{1}$ receptor availability at the same site using the AFNI program 1dCorrelate. First, we tested all voxels within a gray matter mask; we then tested only those voxels within regions showing significant GMV differences between cannabis users and controls.

Gene expression. Associations between the spatial distribution of group differences in GMV and expression of the gene that encodes the $C B_{1} R$ were tested with reference to the Allen Human Brain Atlas (Hawrylycz et al., 2012). Using the alleninf toolbox (Gorgolewski et al., 2014) we ex- tracted normalized gene expression values for CNR1 (averaged within spherical ROIs with radii of $3 \mathrm{~mm}$ ) from within a gray matter mask and then used random-label permutation to test for an association between CNR1 expression and the $t$ statistic of GMV effects. Distributions of Spearman correlations between 50 randomly selected genes and the $t$ statistics of GMV effects were obtained by 5000 bootstrap resamples and then merged to build a null model. The $95 \%$ confidence interval of this null distribution was calculated as the cutoff point against which the strength of the association between GMV effects and CNR1 gene expression was assessed. The list of randomly chosen genes, their expression at each sampling site, the expression of CNR1, and the GMV $t$ statistic at each sampling site are available in Extended Data Tables 1-3, available at https://doi.org/10.1523/JNEUROSCI.3375-17.2018.t1-1; https:// doi.org/10.1523/JNEUROSCI.3375-17.2018.t1-2; https://doi.org/ 10.1523/JNEUROSCI.3375-17.2018.t1-3.

\section{Results}

\section{Cohort 1: group differences in GMV associated with low rates} of cannabis use

Figure 1 illustrates extensive regions of greater GMV in those participants who reported low levels of cannabis use relative to matched controls. Bilateral medial temporal regions, including the hippocampus, the amygdala, and the striatum, and bilateral parietal regions were implicated, as were regions of the cerebellum and the left middle temporal gyrus (Table 4). Because of the relevance of the striatal subregions, especially the ventral striatum, for addiction and substance use, Table 5 details the number of voxels (and proportion of volume) implicated in each of the putamen, caudate, and ventral striatum as defined by the OxfordGSK-Imanova structural striatal atlas (Tziortzi et al., 2011). Figure 2 illustrates the distribution of regional GMV, normalized by total GMV, for those regions at which GMV differed between cannabis users and controls.

Of all the variables describing cognitive ability, symptoms of psychopathology, and personality, only agoraphobia $(U=$ $\left.868.00, p_{\text {uncorr }}=0.038\right)$ and the sensation seeking measure from the SURPS $\left(t_{(88)}=2.824, p_{\text {uncorr }}=0.006\right)$ differed between the cannabis users and controls with the cannabis users reporting higher levels of both. When agoraphobia band score and sensation seeking were included in the voxelwise analysis as covariates, the three clusters reported in Figure 1 and Table 4 were still observed (albeit, with a small reduction in volume that may be accounted for by the reduction in power because of the addition of extra covariates). One additional cluster centered on the left inferior temporal gyrus (Table 6) was also revealed in this analysis as showing significantly greater GMV in the cannabis users than the controls.

\section{Cohort 1: associations between GMV and contemporaneous behavioral measures}

In light of the individual differences in normalized GMV effects in the cannabis using group, we conducted post hoc analyses to explore whether any of the demographic variables on which the groups were matched was associated with GMV in the ROIs for those adolescents reporting cannabis use. Age was not associated with normalized GMV in any of the identified ROIs; the difference between males and females in GMV in the bilateral parietal cluster approached but did not reach the corrected significance level $\left(t_{(44)}=2.226 p_{\text {uncorr }}=0.031\right)$ with normalized GMV greater in males than females. When controlling for handedness, sex, and age, normalized GMV in the left and right temporal clusters $\left(r_{(41)}\right.$ $=-0.411, p_{\text {corr }}=0.037$ and $r_{(41)}=-0.457, p_{\text {corr }}=0.012$, respectively) were negatively associated with PRIQ such that greater relative volume in these regions was associated with re- 


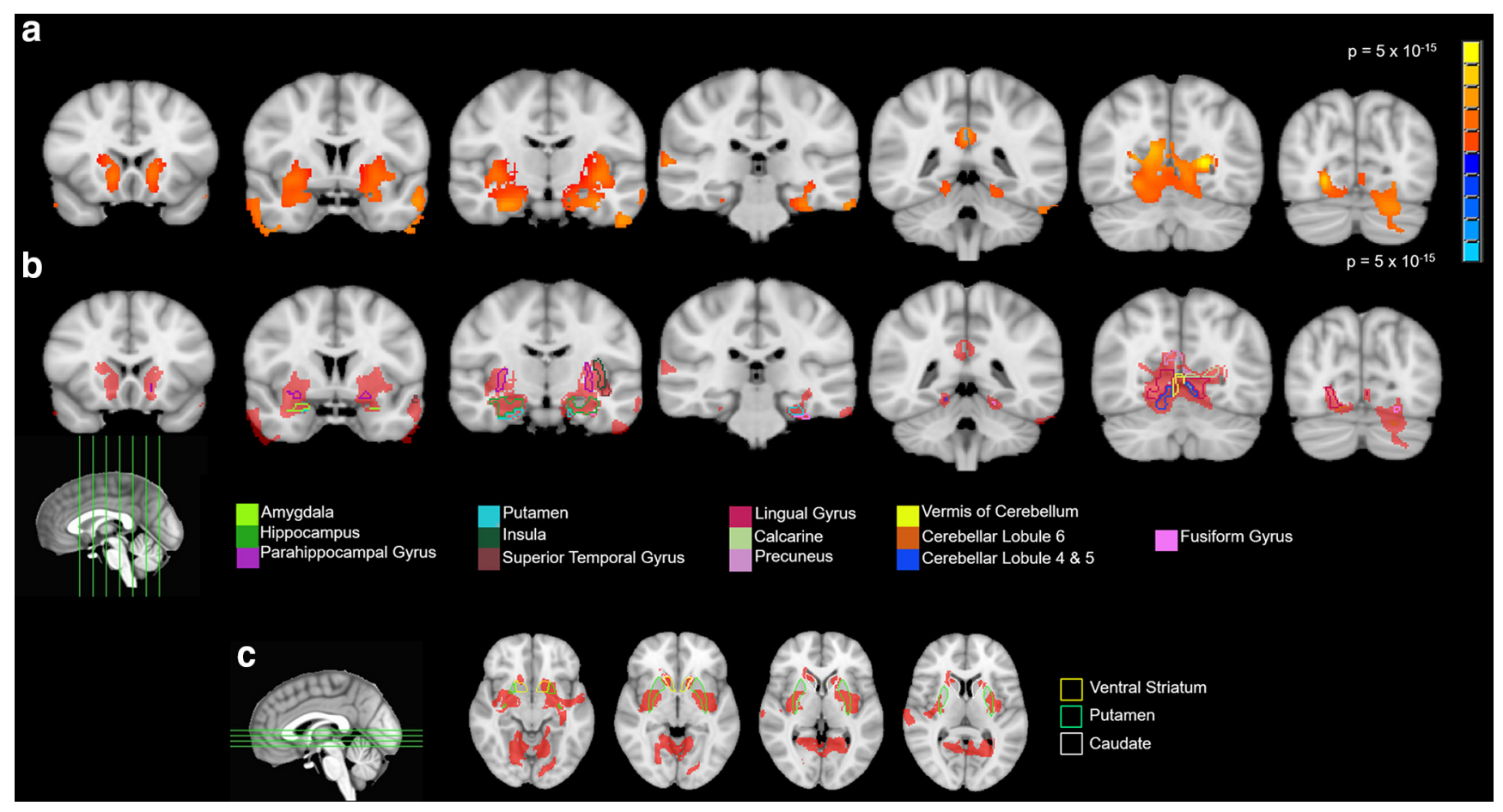

Figure 1. $a$, Those regions showing significantly greater GMV in 14-year-olds reporting one or two instances of cannabis use than in matched controls $\left(p_{\mathrm{FWE}}<0.05\right)$. From left to right, slices are taken from anterior $(y=-18)$ to posterior $(y=72)$ in $15 \mathrm{~mm}$ increments. The left hemisphere is to the right of the image. $\boldsymbol{b}$, Outlines of anatomical regions (AAL atlas) superimposed on a binarized mask of the voxels showing significantly greater GMV in 14-year-olds reporting one or two instances of cannabis use than in matched controls $\left(p_{\mathrm{FWE}}<0.05\right)$. For clarity, only those regions for which at least $10 \%$ of their volume was included in the significant clusters are represented. From left to right, slices are taken from anterior $(y=-18)$ to posterior $(y=72)$ in $15 \mathrm{~mm}$ increments. The left hemisphere is to the right of the image. c, Outlines of striatal subregions (Oxford-GSK-Imanova structural striatal atlas; Tziortzi et al., 2011) superimposed on a binarized mask of the voxels showing significantly greater GMV in 14 -year-olds reporting one or two instances of cannabis use than in matched controls $\left(p_{\mathrm{FWF}}<0.05\right)$. From left to right, slices are taken from inferior $(z=-10)$ to superior $(z=8)$ in $6 \mathrm{~mm}$ increments. The left hemisphere is to the right of the image.

duced PRIQ (Fig. 3). VCIQ, PDS, SES, alcohol use, and nicotine use were not associated with GMV in any of the identified ROIs. The cannabis use metrics (age of use or whether cannabis was used in the last month) were not associated with GMV.

Of the specific cognitive and psychological domains assessed at baseline, only psychomotor speed showed an association with GMV (Fig. 4): normalized GMV in the left temporal cluster showed a negative association with the number of pegs placed with the non-dominant hand $\left(r_{(39)}=-0.454, p_{\text {corr }}=0.030\right)$.

Cohort 2: associations between GMV and future cannabis use There were no regions at which GMV differed between the future cannabis users and their matched controls. ROI analyses focused on those regions from Cohort 1 that differed between baseline users and matched controls also revealed no significant differences between future cannabis users and matched controls (Table 7).

\section{Cohort 1: associations between GMV and future} behavioral measures

A post hoc Mann-Whitney $U$ test showed that baseline GMV in the right temporal cluster was significantly greater for those cannabis users who went on to have higher levels of generalized anxiety (DAWBA band scores of 1 or greater vs DAWBA band scores of 0: $U=43, p_{\text {corr }}=0.009$, Fig. 5). No other associations between regional GMV and cognition or psychopathology reached significance.
Cohort 1: spatial associations between GMV effects and $\mathrm{CB}_{1}$ receptor availability

Comparison of the $t$ statistic map of GMV differences between cannabis users and controls with the map of average $\mathrm{CB}_{1}$ receptor availability in an independent sample (D'Souza et al., 2016) showed significant $(p<0.05)$ spatial association $\left(r_{(54,041)}=\right.$ $0.1131,95 \%$ CI: $0.10468,0.12152)$. Comparison of only those voxels showing a significant GMV difference between cannabis users and controls also showed a significant $(p<0.05)$ spatial association between the magnitude of GMV effects and $\mathrm{CB}_{1}$ receptor availability $\left(r_{(1229)}=0.0803,95 \%\right.$ CI: $\left.0.02537,0.13444\right)$. This more conservative test illustrates that even within those regions showing a significant GMV difference between cannabis users and controls, the magnitude of the difference was associated with $\mathrm{CB}_{1}$ receptor availability.

Cohort 1: spatial associations between GMV effects and CNR1 gene expression

Comparison of the $t$ statistic map of GMV differences between cannabis users and controls with the map of CNR1 gene expression showed significant $(p<0.05)$ spatial association $\left(r_{(3685)}=\right.$ $0.311,95 \%$ CI: $0.279,0.341)$, while the null model showed no association with GMV (95\% CI: -01930, 01977).

\section{Discussion}

We present evidence of GMV differences in adolescents associated with only one or two instances of cannabis use. Although novel, this work is consistent with reports of a dose-response effect of cannabis on behavioral and brain measures following 
Table 4. Those regions showing significantly greater GMV in 14 year olds reporting 1 or 2 instances of cannabis use than in matched controls

\begin{tabular}{lll}
\hline & No. of & Anatomical \\
significant & region \\
Anatomical region (AAL) & voxels & implicated, \% \\
\hline
\end{tabular}

Cluster 1: left temporal (Vol. 4968 vox; 16,767 $\mu$ l;

$$
F_{(1,80)}=8.88, p_{\text {corr }}=0.008 \text {; }
$$$$
\text { peak voxel }-55,-2,-14 \text { ) }
$$$$
\text { Frontal lobe }
$$

$$
\text { Olfactory cortex }
$$

Gyrus rectus

Superior frontal gyrus (pars orbitalis)

Inferior frontal gyrus (pars orbitalis)

Temporal lobe

Superior temporal gyrus $\quad 420$

Middle temporal gyrus 164

Heschl's gyrus

Superior temporal pole

Rolandic operculum

Inferior temporal gyrus

Subcortical

Amygdala

Hippocampus

Putamen

Pallidum

Insula

ParaHippocampal gyrus

Caudate

Cluster 2: Right temporal (Vol. 3710 vox; 12,491 $\mu$ l);

$\mathrm{F}_{(1,80)}=5.88, p_{\text {corr }}=0.018$;

peak voxel $30,-11,-27$ )

Temporal lobe

Heschl's gyrus

Superior temporal gyrus

Superior temporal pole

Subcortical

Amygdala

Hippocampus

Pallidum

Putamen

Parahippocampal gyrus

Insula

Cluster 3: Bilateral Posterior (Vol. 4959 vox; 16,737 $\mu \mathrm{l})$;

$F_{(1,80)}=14.32, \mathrm{p}_{\text {corr }}=8.0 \times 10^{-4}$;

peak voxel $-24,-59,3)$

Temporal lobe

Fusiform gyrus (L)

Fusiform gyrus (R)

Parietal lobe

Posterior cingulate (R)

Posterior cingulate (L)

Precuneus (R)

Precuneus (L)

Occipital lobe

Lingual gyrus (R)

Lingual gyrus (L)

Calcarine (L)

Calcarine (R)

Cerebellum

Cerebellar vermis (45)

Cerebellar lobule 45 (R)

Cerebellar lobule 6 (L)

Cerebellar lobule 6 (R)

Cerebellar lobule 45 (L)

Cerebellar vermis (6)

Crus cerebellum1 (L)
20.57

2.33

1.34

0.95

7.87

1.38

0.55

0.43

0.21

0.07

74.17

35.63

21.13

18.13

14.79

8.56

4.08

6202
92

11.62

0.67

0.54

73.91

33.13

26.46

22.20

15.61

4.39

410

185
Table 5. The number of ventral striatum voxels (and percentage of total anatomical volume) showing significantly greater GMV in 14 year olds reporting 1 or 2 instances of cannabis use than in matched controls

\begin{tabular}{lll}
\hline & $\begin{array}{l}\text { No. of significant } \\
\text { voxels }\end{array}$ & $\begin{array}{l}\text { Anatomical region } \\
\text { implicated, \% }\end{array}$ \\
\hline Ventral striatum, left & 131 & 30.32 \\
Ventral striatum, right & 226 & 54.72 \\
\hline
\end{tabular}

heavier use (Lorenzetti et al., 2010; Silins et al., 2014). We identified significantly greater GMV in adolescents who reported only one or two instances of cannabis use relative to cannabis naive controls in large medial temporal clusters incorporating the amygdala, hippocampus, and striatum, extending into the left prefrontal cortex. Significantly greater GMV was also observed in the lingual gyri, posterior cingulate, and cerebellum. The regions identified in this whole-brain, VBM approach replicated previous findings of differences in volume (Yücel et al., 2008; Ashtari et al., 2011; Schacht et al., 2012) and shape (Gilman et al., 2014; Smith et al., 2014, 2015) associated with cannabis use in ROI studies and with the spatial distribution of the $\mathrm{eCB}$ system (Burns et al., 2007). Although cannabis use has been associated with reduced brain volumes, studies typically report on adults with heavy substance use histories (cf. Ashtari et al., 2011). Gilman et al. (2014), however, have reported gray-matter density increases in the amygdala and nucleus accumbens of young adult recreational users and Medina et al. (2007) observed hippocampal enlargement in cannabis using adolescents. Our results are also consistent with the Avon Longitudinal Study of Parents and Children (French et al., 2015), which showed a trend for greater cortical thickness in male adolescents with $<5$ instances of cannabis use relative to THC-naive controls.

Converging evidence suggests that these effects may be a consequence of cannabis exposure. GMV differences could not be explained by group differences in demographic, personality, psychopathology, or other substance use factors. Examination of THC-naive 14-year-olds who later used cannabis showed no GMV differences, even using a more liberal ROI test, suggesting that the differences do not precede cannabis use and are not because of unidentified factors in those predisposed to use. Finally, the spatial distribution of GMV effects was associated with the eCB system, suggesting cannabis exposure may cause these findings.

The preclinical literature presents a number of possible mechanisms by which low levels of cannabis exposure could result in greater GMV relative to THC-naive controls. Adolescent rats treated with cannabinoid agonist showed altered gliogenesis in regions including the striatum and greater preservation of oligodendroglia relative to control animals (Bortolato et al., 2014). Zebra finches treated with cannabinoid agonist showed greater dendritic spine densities (Gilbert and Soderstrom, 2011); critically, these effects were observed in late-prenatal but not adult animals. Of particular relevance to this study, a single dose of $\triangle 9 \mathrm{THC}$ transiently abolished eCB-mediated long-term depression (LTD) in the nucleus accumbens and hippocampus of adolescent mice (Mato et al., 2004). Suspension of LTD may interrupt maturation-related neural pruning and preserve gray matter. Future studies should assess whether these processes operate in human adolescents and whether they produce persisting alterations in GMV.

These findings should be interpreted in light of the study's limitations. The IMAGEN sample is racially and ethnically homogenous so it remains to be determined whether the findings 


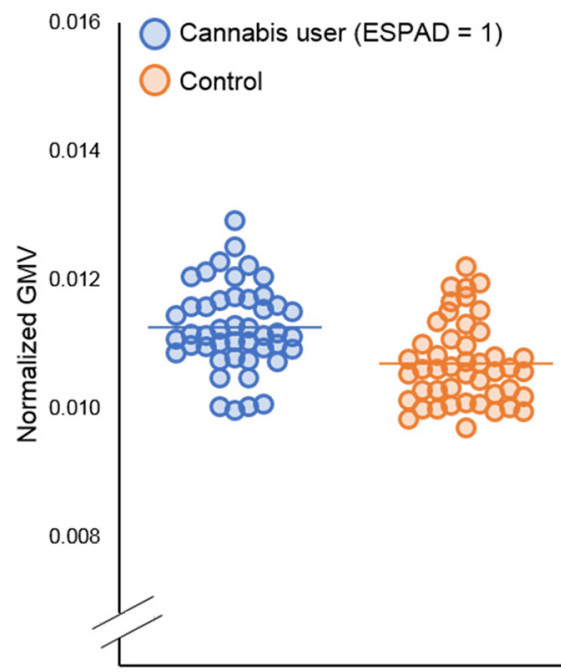

Left Temporal Cluster

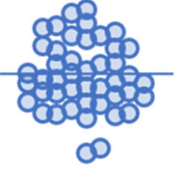

Right Temporal Cluster

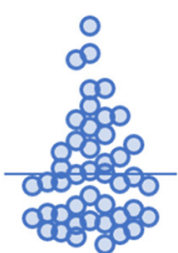

O

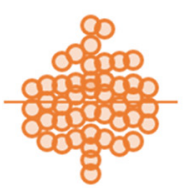

Bilateral Parietal Cluster

Figure 2. Distribution of Average GMV in the regions showing significantly different GMV between those 14-year-olds reporting one or two instances of cannabis use and matched controls.

Table 6. Those regions showing significantly greater GMV in 14 year olds reporting 1 or 2 instances of cannabis use than in matched controls, when controlling for agoraphobia and sensation seeking

\begin{tabular}{llcl}
\hline Region & Vol & Peak voxel & \\
\hline Left temporal & $4836 \mathrm{v} 0 \mathrm{x}(16,321 \mu \mathrm{l})$ & $-55,-2,-14$ & $F_{(1,76)}=8.018, p_{\text {corr }}=0.011$ \\
Right temporal & $3425 \mathrm{v} 0 \mathrm{x}(11,559 \mu \mathrm{l})$ & $30,-11,-27$ & $F_{(1,76)}=6.026, p_{\text {corr }}=0.016$ \\
$\begin{array}{c}\text { Bilateral posterior/ } \\
\quad \text { inferior parietal }\end{array}$ & $4907 \mathrm{v} 0 \mathrm{x}(16,561 \mu \mathrm{l})$ & $-24,-59,3$ & $F_{(1,76)}=12.718, p_{\text {corr }}=0.002$ \\
$\begin{array}{c}\text { Left inferior } \\
\quad \text { temporal gyrus }\end{array}$ & $603 \mathrm{vox}(2,038 \mu \mathrm{l})$ & $-50,-9,-42$ & $F_{(1,76)}=12.755, p_{\text {corr }}=0.002$ \\
\hline
\end{tabular}

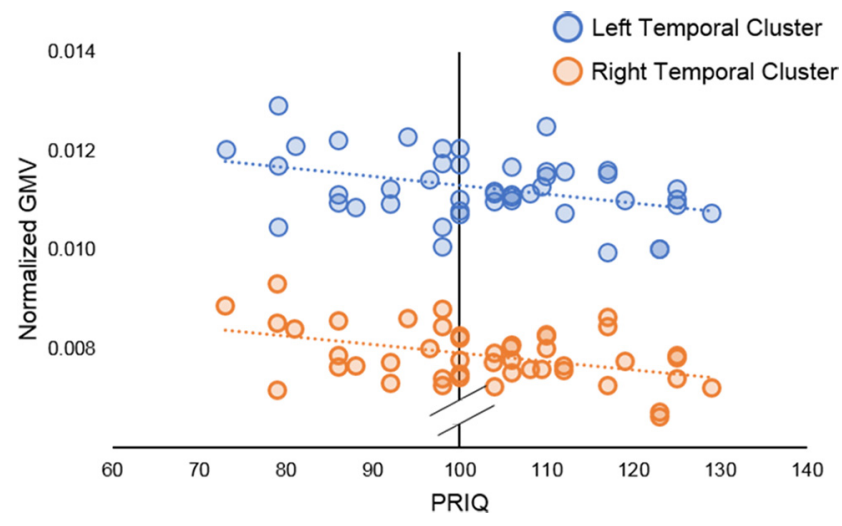

Figure 3. Inverse correlations were observed between PRIQ and normalized GMV in the left $\left(r_{(41)}=-0.411, p_{\text {corr }}=0.037\right)$ and right $\left(r_{(41)}=-0.457, p_{\text {corr }}=0.012\right)$ temporal clusters for those participants reporting one or two instances of cannabis use.

generalize to youth from more diverse backgrounds. Substance use was assessed using self-report and we do not have standard dose units of cannabis nor information on mode of use or a measure of drug metabolites. Combining images from different sites and imaging platforms remains controversial and is not completely controlled by including site as a covariate. Future studies should replicate the present results using images acquired at the same site on the same scanner or with equal numbers of cases and controls per scanner. We also note that the CNR1 gene expression (Hawrylycz et al., 2012) and $\mathrm{CB}_{1}$ receptor density (D'Souza et al., 2016) maps were generated in independent samples of adults and may not accurately represent the eCB system in

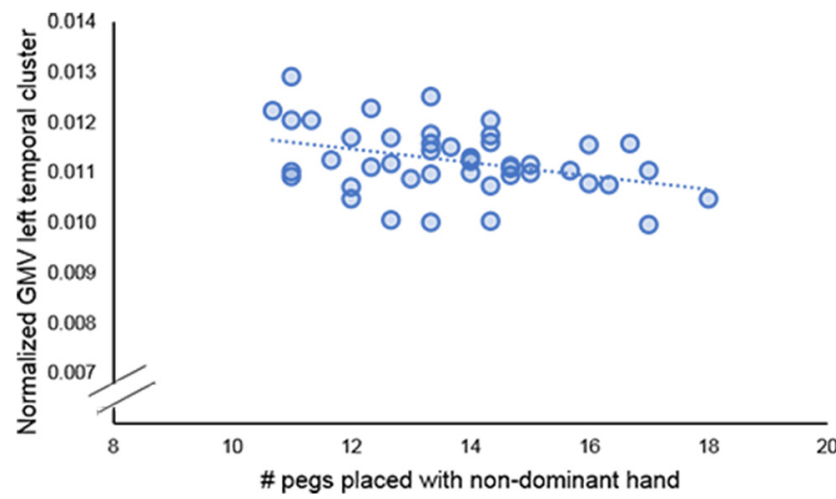

Figure 4. An inverse correlation was observed between normalized GMV in the left temporal cluster and contemporaneous pegboard performance in those participants reporting one or two instances of cannabis use $\left(r_{(39)}=-0.454, p_{\text {corr }}=0.030\right)$.

Table 7. No significant GMV differences were observed at baseline between those participants who were abstinent for cannabis use at age 14 but reported at least 10 instances of use by age 16 and matched controls (i.e., Cohort 2) in those regions defined in Cohort 1

\begin{tabular}{llcl}
\hline Region & Vol & Peak voxel & \\
\hline Left temporal & 4968 vox $(16,767 \mu l)$ & $-55,-2,-14$ & $F_{(1,125)}=3.026, p_{\text {corr }}=0.252$ \\
Right temporal & 3710 vox $(12,491 \mu l)$ & $30,-11,-27$ & $F_{(1,125)}=5.626, p_{\text {corr }}=0.057$ \\
$\begin{array}{c}\text { Bilateral posterior/ } \\
\quad \text { inferior parietal }\end{array}$ & 4959 vox $(16,737 \mu l)$ & $-24,-59,3$ & $F_{(1,125)}=0.021, p_{\text {corr }} \approx 1$ \\
\hline
\end{tabular}

our sample of adolescents. Although we report significant spatial associations between GMV effects and both CNR1 gene expression and $\mathrm{CB}_{1}$ receptor density, the effect sizes were small and any suggestion that these associations represent mechanisms for the effects we observe is speculative and requires further investigation.

We adopted a whole-brain, VBM approach to detect effects that were not limited by anatomical boundaries and to allow exploration of spatial relationships between GMV effects and the eCB system. There is evidence, however, that brain perfusion can influence VBM measures of local volume (Franklin et al., 2013, 2015; Ge et al., 2017; cf. Hawkins et al., 2018) so future studies should combine VBM with other measures of brain structure to 


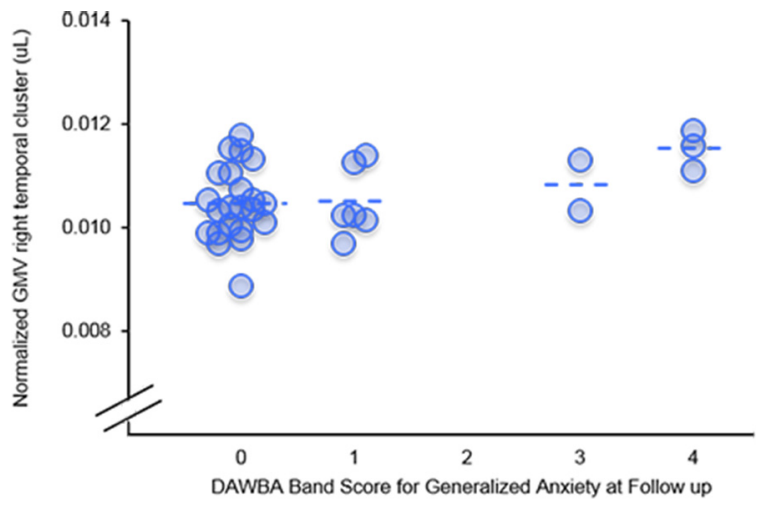

Figure 5. Associations between normalized GMV in the right temporal cluster at baseline and Generalized Anxiety Disorder DAWBA band scores at follow-up. For those participants reporting one or two instances of cannabis use at baseline, those with DAWBA band scores of zero at follow-up had significantly lower GMV at baseline than those with DAWBA band scores of 1 or greater at follow-up $\left(U=43, p_{\text {corr }}=0.009\right)$.

provide confirmatory evidence. In particular, shape analysis has been shown to be sensitive to brain structural differences associated with cannabis use (Gilman et al., 2014; Smith et al., 2014, 2015; Weiland et al., 2015). Moreover, combining morphometry metrics allows for testing of associations between them, which can identify different relationships between shape deformations and local volume (Gilman et al., 2014) providing evidence of further differences between cannabis users and controls.

One source of variability in the human findings on brain structural correlates of cannabis use may be comorbid substance use (Weiland et al., 2015; Gillespie et al., 2018). Given recent evidence of different patterns of functional connectivity in groups using alcohol, nicotine, and cannabis alone and in combination (Vergara et al., 2018), it will be important to account for any possible interaction effects of cannabis with other psychoactive substances. This issue is particularly important considering the ways in which comorbid substance use has been addressed in two recent, widely cited studies. Gilman et al. (2014) covaried for alcohol and nicotine use and found gray-matter density increases and shape deformations associated with cannabis use. Weiland et al. (2015) matched groups on alcohol and nicotine use and reported no morphometric differences associated with cannabis use, concluding that previously reported differences associated with cannabis may instead be attributable to alcohol use. The participants in Weiland et al.'s (2015) study, however, were using alcohol and nicotine at higher levels than those in Gilman et al.'s (2014) study. It is possible that cannabis, alcohol, and nicotine have differential effects on brain morphometry; specifically, recreational cannabis use has been associated with volume increases, whereas alcohol has been associated with volume reductions. In the current study, we matched the groups on alcohol and nicotine use and, within the cannabis using group, neither alcohol nor nicotine use was associated with individual differences in GMV, suggesting that the GMV differences we report are associated with cannabis use.

We note individual differences in GMV effects: although regional GMV was greater at the group level for adolescents with low levels of cannabis exposure, the distributions showed a high degree of overlap such that many cannabis users had GMV equivalent to that of controls. None of the tested demographic, personality, or substance use factors stratified GMV in the cannabis users. We note evidence that an association between cannabis use and cortical thickness was stratified by genetic risk for schizo- phrenia (French et al., 2015) and that an association between cannabis use and hippocampal shape was stratified by dopaminerelevant genes (Batalla et al., 2018). Some adolescents may be vulnerable to GMV effects at extremely low levels of cannabis use and it will be critical to identify those at risk as these structural brain changes may be associated with individual risk for psychopathology and deleterious effects on mood and cognition.

Of the behavioral variables tested, only sensation seeking and agoraphobia differed between the cannabis users and controls and these factors were not related to GMV differences. In the cannabis using participants, GMV in the medial temporal clusters was associated with PRIQ and psychomotor speed such that greater GMV in these regions was associated with reduced performance. The finding that right medial temporal GMV predicted generalized anxiety symptoms at follow-up for those participants who had used cannabis should be interpreted with caution given the small sample size and that we were not able to identify factors that drove the individual differences in cannabis effects on GMV at baseline. These findings are notable, however, as panic and anxiety symptoms are frequently reported side effects by naive and occasional cannabis users (Hall and Solowij, 1998). We also note fMRI evidence of hypersensitivity of the amygdala to signals of threat in a partly overlapping sample of cannabis using adolescents (Spechler et al., 2015) and a relationship between adolescent cannabis use and future mood complaints (Wittchen et al., 2007), even with comparatively low levels of use (Cheung et al., 2010).

We have revealed greater GMV in adolescents with only one or two instances of cannabis use in regions rich in $\mathrm{CB}_{1}$ receptors and CNR1 gene expression. Critically, we were able to control for a range of demographic and substance use effects, to confirm that these structural brain effects were not associated with comorbid psychopathology, and to demonstrate that these effects were unlikely to precede cannabis use. The pattern of results is characterized by individual differences in GMV effects in the cannabis users; these individual differences were associated with PRIQ and with vulnerability to future symptoms of generalized anxiety. Given the increasing levels of cannabis use among adolescents today, we suggest that studying the effects of recreational use early in life is an area of particular importance that should be addressed in the future by large scale, prospective studies.

\section{References}

Ashburner J (2007) A fast diffeomorphic image registration algorithm. Neuroimage 38:95-113.

Ashburner J, Friston KJ (2000) Voxel-based morphometry: the methods. Neuroimage 11:805-821.

Ashtari M, Avants B, Cyckowski L, Cervellione KL, Roofeh D, Cook P, Gee J, Sevy S, Kumra S (2011) Medial temporal structures and memory functions in adolescents with heavy cannabis use. J Psychiatr Res 45:10551066.

Batalla A, Lorenzetti V, Chye Y, Yücel M, Soriano-Mas C, Bhattacharyya S, Torrens M, Crippa JA, Martín-Santos R (2018) The influence of DAT1, COMT, and BDNF genetic polymorphisms on total and subregional hippocampal volumes in early onset heavy cannabis users. Cannabis Cannabinoid Res 3:1-10.

Battistella G, Fornari E, Annoni JM, Chtioui H, Dao K, Fabritius M, Favrat B, Mall JF, Maeder P, Giroud C (2014) Long-term effects of cannabis on brain structure. Neuropsychopharmacology 39:2041-2048.

Bortolato M, Bini V, Frau R, Devoto P, Pardu A, Fan Y, Solbrig MV (2014) Juvenile cannabinoid treatment induces frontostriatal gliogenesis in lewis rats. Eur Neuropsychopharmacol 24:974-985.

Burns HD, Van Laere K, Sanabria-Bohórquez S, Hamill TG, Bormans G, Eng WS, Gibson R, Ryan C, Connolly B, Patel S, Krause S, Vanko A, Van Hecken A, Dupont P, De Lepeleire I, Rothenberg P, Stoch SA, Cote J, 
Hagmann WK, Jewell JP, et al. (2007) [18 $\left.{ }^{\mathrm{F}}\right]$ MK-9470, a positron emission tomography (PET) tracer for in vivo human PET brain imaging of the cannabinoid-1 receptor. Proc Natl Acad Sci U S A 104:9800-9805.

Cheung JT, Mann RE, Ialomiteanu A, Stoduto G, Chan V, Ala-Leppilampi K, Rehm J (2010) Anxiety and mood disorders and cannabis use. Am J Drug Alcohol Abuse 36:118-122.

Cloninger CR, Przybeck TR, Svrakic DM, Wetzel RD (1994) The Temperament and Character Inventory (TCI): A guide to its development and use, pp 19-28. St-Louis, MO: Washington University.

Costa PT, McCrae RR (1992) Normal personality assessment in clinical practice: The NEO Personality Inventory. Psychological assessment 4:5-13.

Cousijn J, Wiers RW, Ridderinkhof KR, van den Brink W, Veltman DJ, Goudriaan $\mathrm{AE}$ (2012) Grey matter alterations associated with cannabis use: results of a VBM study in heavy cannabis users and healthy controls. Neuroimage 59:3845-3851.

Cox RW (1996) AFNI: software for analysis and visualization of functional magnetic resonance neuroimages. Comput Biomed Res 29:162-173.

Curran HV, Freeman TP, Mokrysz C, Lewis DA, Morgan CJ, Parsons LH (2016) Keep off the grass? Cannabis, cognition and addiction. Nat Rev Neurosci 17:293-306.

Downer E, Boland B, Fogarty M, Campbell V (2001) $\Delta 9$-Tetrahydrocannabinol induces the apoptotic pathway in cultured cortical neurones via activation of the CB1 receptor. Neuroreport 12:3973-3978.

D'Souza DC, Cortes-Briones JA, Ranganathan M, Thurnauer H, Creatura G, Surti T, Planeta B, Neumeister A, Pittman B, Normandin MD (2016) Rapid changes in cannabinoid 1 receptor availability in cannabisdependent male subjects after abstinence from cannabis. Biol Psychiatry Cogn Neurosci Neuroimaging 1:60-67.

Eklund A, Nichols TE, Knutsson H (2016) Cluster failure: why fMRI inferences for spatial extent have inflated false-positive rates. Proc Natl Acad Sci U S A 113:7900-7905.

Fernández-Ruiz J, Berrendero F, Hernández ML, Ramos JA (2000) The endogenous cannabinoid system and brain development. Trends Neurosci 23:14-20.

Franklin TR, Wang Z, Shin J, Jagannathan K, Suh JJ, Detre JA, O’Brien CP, Childress AR (2013) A VBM study demonstrating "apparent" effects of a single dose of medication on T1-weighted MRIs. Brain Struct Funct 218:97-104.

Franklin TR, Wetherill RR, Jagannathan K, Hager N, O’Brien CP, Childress AR (2015) Limitations of the use of the MP-RAGE to identify neural changes in the brain: recent cigarette smoking alters gray matter indices in the striatum. Front Hum Neurosci 8:1052.

French L, Gray C, Leonard G, Perron M, Pike GB, Richer L, Séguin JR, Veillette S, Evans CJ, Artiges E, Banaschewski T, Bokde AW, Bromberg U, Bruehl R, Buchel C, Cattrell A, Conrod PJ, Flor H, Frouin V, Gallinat J, et al. (2015) Early cannabis use, polygenic risk score for schizophrenia and brain maturation in adolescence. JAMA Psychiatry 72:1002-1011.

Ge Q, Peng W, Zhang J, Weng X, Zhang Y, Liu T, Zang YF, Wang Z (2017) Short-term apparent brain tissue changes are contributed by cerebral blood flow alterations. PloS One 12:e0182182.

Gilbert MT, Soderstrom K (2011) Late-postnatal cannabinoid exposure persistently elevates dendritic spine densities in area X and HVC song regions of zebra finch telencephalon. Brain Res 1405:23-30.

Gillespie NA, Neale MC, Bates TC, Eyler LT, Fennema-Notestine C, Vassileva J, Lyons MJ, Prom-Wormley EC, McMahon KL, Thompson PM, de Zubicaray G, Hickie IB, McGrath JJ, Strike LT, Rentería ME, Panizzon MS, Martin NG, Franz CE, Kremen WS, Wright MJ (2018) Testing associations between cannabis use and subcortical volumes in two large population-based samples. Addiction, 113:1661-1672.

Gilman JM, Kuster JK, Lee S, Lee MJ, Kim BW, Makris N, van der Kouwe A, Blood AJ, Breiter HC (2014) Cannabis use is quantitatively associated with nucleus accumbens and amygdala abnormalities in young adult recreational users. J Neurosci 34:5529-5538.

Goodman R, Ford T, Richards H, Gatward R, Meltzer H (2000) The development and well-being assessment: description and initial validation of an integrated assessment of child and adolescent psychopathology. J Child Psychol Psychiatry 41:645-655.

Gorgolewski K, Fox A, Chang L, Schäfer A, Arélin K, Burmann I, Sacher J, Margulies D (2014) Tight fitting genes: finding relations between statistical maps and gene expression patterns. F1000Posters 5:1607.

Hall W, Solowij N (1998) Adverse effects of cannabis. Lancet 352:16111616.
Hawkins PC, Wood TC, Vernon AC, Bertolino A, Sambataro F, Dukart J, Merlo-Pich E, Risterucci C, Silber-Baumann H, Walsh E, Mazibuko N, Zelaya FO, Mehta MA (2018) An investigation of regional cerebral blood flow and tissue structure changes after acute administration of antipsychotics in healthy male volunteers. Hum Brain Mapp 39:319-331.

Hawrylycz MJ, Lein ES, Guillozet-Bongaarts AL, Shen EH, Ng L, Miller JA, Van De Lagemaat LN, Smith KA, Ebbert A, Riley ZL, Abajian C, Beckmann CF, Bernard A, Bertagnolli D, Boe AF, Cartagena PM, Chakravarty MM, Chapin M, Chong J, Dalley RA, et al. (2012) An anatomically comprehensive atlas of the adult human brain transcriptome. Nature 489:391.

Hibell B, Andersson B, Bjarnason T, Ahlström S, Balakireva O, Kokkevi A, Morgan M (2004) The ESPAD report 2003: alcohool and other drug use among students in 35 European countries. Stockholm: Swedish Council for Information on Alcohol and Other Drugs

Jager G, Van Hell HH, De Win MM, Kahn RS, Van Den Brink W, Van Ree JM, Ramsey NF (2007) Effects of frequent cannabis use on hippocampal activity during an associative memory task. Eur Neuropsychopharmacol 17:289-297.

Kirby KN (2009) One-year temporal stability of delay-discount rates. Psychon Bull Rev 16:457-462.

Lorenzetti V, Lubman DI, Whittle S, Solowij N, Yücel M (2010) Structural MRI findings in long-term cannabis users: what do we know? Substance Use Misuse 45:1787-1808.

Lorenzetti V, Solowij N, Yücel M (2016) The role of cannabinoids in neuroanatomic alterations in cannabis users. Biol Psychiatry 79:e17-e31.

Lubman DI, Cheetham A, Yücel M (2015) Cannabis and adolescent brain development. Pharmacol Ther 148:1-16.

Mato S, Chevaleyre V, Robbe D, Pazos A, Castillo PE, Manzoni OJ (2004) A single in-vivo exposure to $\triangle 9 \mathrm{THC}$ blocks endocannabinoid-mediated synaptic plasticity. Nat Neurosci 7:585-586.

Medina KL, Schweinsburg AD, Cohen-Zion M, Nagel BJ, Tapert SF (2007) Effects of alcohol and combined marijuana and alcohol use during adolescence on hippocampal volume and asymmetry. Neurotoxicol Teratol 29:141-152.

Panlilio LV, Justinova Z (2018) Preclinical studies of cannabinoid reward, treatments for cannabis use disorder, and addiction-related effects of cannabinoid exposure. Neuropsychopharmacology 43:116-141.

Petersen AC, Crockett L, Richards M, Boxer A (1988) A self-report measure of pubertal status: reliability, validity, and initial norms. J Youth Adolesc $17: 117-133$

Robbins TW, James M, Owen AM, Sahakian BJ, McInnes L, Rabbitt P (1994) Cambridge neuropsychological test automated battery (CANTAB): a factor analytic study of a large sample of normal elderly volunteers. Dementia 5:266-281.

Rubino T, Parolaro D (2008) Long lasting consequences of cannabis exposure in adolescence. Mol Cell Endocrinol 286:S108-S113.

Lipari RN, Hedden SL, Hughes A (2014) Substance and mental health estimates from the 2013 national survey on drug use and health: overview of findings. The CBHSQ Report. Rockville, MD: Substance Abuse and Mental Health Services Administration.

Schacht JP, Hutchison KE, Filbey FM (2012) Associations between cannabinoid receptor-1 (CNR1) variation and hippocampus and amygdala volumes in heavy cannabis users. Neuropsychopharmacology 37:2368 2376.

Schumann G, Loth E, Banaschewski T, Barbot A, Barker G, Büchel C, Conrod P, Dalley J, Flor H, Gallinat J, Garavan H, Heinz A, Itterman B, Lathrop M, Mallik C, Mann K, Martinot JL, Paus T, Poline JB, Robbins TW, et al. (2010) The IMAGEN study: reinforcement-related behaviour in normal brain function and psychopathology. Mol Psychiatry 15:1128-1139.

Silins E, Horwood LJ, Patton GC, Fergusson DM, Olsson CA, Hutchinson DM, Spry E, Toumbourou JW, Degenhardt L, Swift W, Coffey C, Tait RJ, Letcher P, Copeland J, Mattick RP, Mattick RP (2014) Young adult sequelae of adolescent cannabis use: an integrative analysis. Lancet Psychiatry 1:286-293.

Smith MJ, Cobia DJ, Wang L, Alpert KI, Cronenwett WJ, Goldman MB, Mamah D, Barch DM, Breiter HC, Csernansky JG (2014) Cannabisrelated working memory deficits and associated subcortical morphological differences in healthy individuals and schizophrenia subjects. Schizophr Bull 40:287-299.

Smith MJ, Cobia DJ, Reilly JL, Gilman JM, Roberts AG, Alpert KI, Wang L, Breiter HC, Csernansky JG (2015) Cannabis-related episodic memory 
deficits and hippocampal morphological differences in healthy individuals and schizophrenia subjects. Hippocampus 25:1042-1051.

Spechler PA, Orr CA, Chaarani B, Kan KJ, Mackey S, Morton A, Snowe MP, Hudson KE, Althoff RR, Higgins ST, Cattrell A, Flor H, Nees F, Banaschewski T, Bokde ALW, Whelan R, Büchel C, Bromberg U, Conrod P, Frouin V, et al. (2015) Cannabis use in early adolescence: evidence of amygdala hypersensitivity to signals of threat. Dev Cogn Neurosci 16:63-70.

Tiffin J (1968) Purdue pegboard examiner manual. Chicago: Science Research Associates.

Tziortzi AC, Searle GE, Tzimopoulou S, Salinas C, Beaver JD, Jenkinson M, Laruelle M, Rabiner EA, Gunn RN (2011) Imaging dopamine receptors in humans with $\left[{ }^{11} \mathrm{C}\right]-(+)-\mathrm{PHNO}$ : dissection of D3 signal and anatomy. Neuroimage 54:264-277.

Vergara VM, Weiland BJ, Hutchison KE, Calhoun VD (2018) The impact of combinations of alcohol, nicotine, and cannabis on dynamic brain connectivity. Neuropsychopharmacology 43:877-890.
Wechsler D (1949) Wechsler intelligence scale for children. New York: Psychological.

Weiland BJ, Thayer RE, Depue BE, Sabbineni A, Bryan AD, Hutchison KE (2015) Daily marijuana use is not associated with brain morphometric measures in adolescents or adults. J Neurosci 35:1505-1512.

Wittchen HU, Fröhlich C, Behrendt S, Günther A, Rehm J, Zimmermann P, Lieb R, Perkonigg A (2007) Cannabis use and cannabis use disorders and their relationship to mental disorders: a 10-year prospectivelongitudinal community study in adolescents. Drug Alcohol Dependence 88:S60-S70.

Woicik PA, Stewart SH, Pihl RO, Conrod PJ (2009) The substance use risk profile scale: A scale measuring traits linked to reinforcement-specific substance use profiles. Addictive behaviors, 34:1042-1055.

Yücel M, Solowij N, Respondek C, Whittle S, Fornito A, Pantelis C, Lubman DI (2008) Regional brain abnormalities associated with longterm heavy cannabis use. Arch Gen Psychiatry 65:694-701. 